\title{
Primary health care social work in Aotearoa New Zealand: An exploratory investigation
}

\author{
Stefanie Döbl, Liz Beddoe and Peter Huggard University of Auckland, New Zealand
}

\begin{abstract}
INTRODUCTION: The social work profession has a long-standing history of contributing to health care in Aotearoa New Zealand. Traditionally, hospitals have been the stronghold for the profession. However, both international and national evidence demonstrates that social workers have also been integrated in primary health care practices (PHCPs). Primary health care (PHC) provides care in the community and is recognised for its potential to achieve health equity across all population groups. This article reports on a small, qualitative research project which explored the perceptions of key stakeholders about social work integration into PHC and the experiences gained by social workers working within PHCPs regarding their contributions to the achievement of national aspirations for PHC.
\end{abstract}

METHODS: Semi-structured, one-to-one interviews with 18 participants representing three groups (social workers, other PHC professionals and key informants) were undertaken in 2012. The interviews took place in various locations in Aotearoa New Zealand. A general inductive approach was used to identify key themes.

FINDINGS: Three key themes were identified from the data: these are issues of context, namely social work professional factors, organisational factors in PHC and lastly, wider factors in the health care system. The integrated social workers enhanced the access of populations to coordinated care, increased engagement with communities, and strengthened the workforce, among other things. These unique contributions towards the PHC vision were well recognised by all groups, with participants calling for the establishment of integrated social work positions on a larger scale.

CONCLUSION: The study evidences the successful integration of social workers into PHC practices in Aotearoa New Zealand. This viable model should be of special interest for key stakeholders regarding the design of local, holistic, PHC services which serve populations most affected by health and social inequalities. Importantly, "health for all", as anticipated by the PHC vision needs long-term and real commitment especially by financial decision-makers.

KEYWORDS: social work; primary health care; integrated care; general practice

The health care system is one of the biggest providers of social work employment in Aotearoa New Zealand, where social workers can be found in preventive, primary, secondary and tertiary health care settings. They practise in a variety of specialities, working with population groups who experience health challenges, and fill frontline to professional leadership positions (Beddoe \& Deeney, 2012; Craig \& Muskat, 2013). While some areas are well known (for example, hospital social work), other domains for health social work are less present in the public eye. One such health care setting is primary health care (PHC).
AOTEAROA

NEW ZEALAND SOCIAL WORK 29(2), 119-130.

CORRESPONDENCE TO: Liz Beddoe

e.beddoe@auckland.ac.nz 
PHC is defined as essential health care provided in the community and represents the first contact point with the health care system (King, 2001). Professional services are offered via primary health care practices (PHCPs) such as general practices, family health centres, union health services, Māori or Pacific health providers. The PHC workforce can include general practitioners, registered nurses, pharmacists, community health workers, social workers, and others.

The Ministry of Health $(\mathrm{MoH})$ in Aotearoa New Zealand has recognised the critical role of PHC as part of the wider health care system. The vision is closely linked to international declarations such as the Alma Ata Declaration (World Health Organization (WHO), 1978) and the Ottawa Charter for Health Promotion (WHO, 1986). Such declarations determine principles which emphasise the importance of PHC in the delivery of fair and equitable health services. The 2001 PHC vision states:

People will be part of local primary health care services that improve their health, keep them well, are easy to get to and co-ordinate their ongoing care. Primary health care services will focus on better health for a population, and actively work to reduce health inequalities between different groups. (King, 2001, p. vii)

The PHC vision and strategy are now 16 years old, and their future is unknown. A new Health Strategy was published by the $\mathrm{MoH}$ in 2016. This far-reaching, high-level policy aligns with other relevant documents (such as the New Zealand Disability Strategy and He Korowai Oranga: Māori Health Strategy) and provides a new direction for the health sector. The aim of this strategy is that New Zealand's whole population lives, stays and gets well by focusing the health care system on five pillars, namely people-power, closer to home services, value and high performance design, working as one team, and providing a smart system (Minister of Health, 2016). While the new strategy mentions important elements of the former health strategy and the current PHC vision such as improving health for all, better integration and collaboration as well as community involvement, it has lost its focus on health inequalities, population health, universal affordability, and social determinants of health among other things. Instead there appears to be a shift to health consumerism, competition, and meeting financial targets by using an investment approach. It remains to be seen how this strategy will impact on PHC on a broader level over the next few years, including the integration of social workers within PHCPs.

A comprehensive and integrated care approach within PHCPs is seen as crucial by the World Health Organization (WHO, 2008). Many definitions can be found regarding this approach (Shaw, Rosen, \& Rumbold, 2011). Essentially, integrated care is based on people-centredness and uses system-wide coordination in order to improve outcomes and quality of care for patients (Curry \& Ham, 2010; Shaw et al., 2011). Coordination which facilitates integrated care occurs in many forms, to various extents and to differing degrees (Curry \& Ham, 2010; Shaw et al., 2011). Flexibility in implementation is encouraged (Shaw et al., 2011) which is sensible as different PCHP populations have widely different needs and resources. One model of integrated care is the positioning of social workers within PHC practices.

The international PHC literature has acknowledged the social work profession's specific theoretical foundations, knowledge and skills, recognising the benefits for a PHCP (Herod \& Lymbery, 2002; Keefe, Geron, \& Enguidanos, 2009). Specific attributes noted include the holistic, ecological views of, and approaches to, health (Brochstein, Adams, Tristan, \& Cheney, 1979; Goldberg, Neill, Speak, \& Faulkner, 1968; Netting \& Williams, 1996; Rock \& Cooper, 2000), a commitment to indigenous models of practice (Brochstein et al., 1979) and extensive community networks (Backett, Maybin, \& Dudgeon, 1957; Dongray, 1958; Goldberg et al., 1968; Lesser, 2000). 
No actual numbers can be found for social work professionals being employed in PHCPs in Aotearoa New Zealand at present with the overall number believed to be small. However, limited evidence in the literature confirms the integration of social workers within PHCPs in Aotearoa New Zealand since the 1970s (Beddoe \& Deeney, 2012; Lowe \& Rainey, 1974; Nuthall \& Craig, 1980). In recent years, several authors have advocated for a change of focus for social work towards an increased contribution to PHC within the health care system (Foster \& Beddoe, 2012; Weld, 2010). For example, Foster and Beddoe (2012) propose a shift of the social work profession in their work with elderly and their families from hospital to PHC settings. They see health social workers' skills better used in the latter settings due to their ability to perform home visits and offering services crossing primary, secondary and residential care. Another author addressing the potential in PHC, Weld (2010), argues that social work is able to confidently address the social determinants of health which often present in PHC. The propositions put forward by these Aotearoa New Zealand authors mirror the policy statement on health by the International Federation of Social Workers (IFSW) which sees a clear role for social work regarding tackling health inequalities. The reason for this is that people's health chances and experiences are influenced by the social determinants of health, available resources and other forces (Bywaters \& Napier, 2008). Further, "[h]ealth and illness are viewed as social experiences, affecting people's identities, relationships and opportunities" (Bywaters \& Napier, 2008, para. 12).

In the international arena, many factors have led to the integration of social workers within PHCPs such as enhanced communication and cooperation between social workers and medical staff (Lesser, 2000) and the strategic provision of timely, early, preventive social care without the need to refer to specialised services (Dongray, 1958; Goldberg et al., 1968; Laden, Oehlers, Waddell, \& Miller, 1983; Wilson
\& Setturlund, 1987). Models of social work in PHC have been shown to ease access for populations such as ethnic minorities and people from a lower socio-economic background, who otherwise may experience barriers to health services (Lesser, 2000; Lymbery \& Millward, 2002; Rizzo \& Mizrahi, 2008). Benefits for people with no experience of, or plans to, access an external social service agency, but who indicated their interest in getting or accepting an offer of support by a PCHP social worker, were also reported (Bikson, McGuire, Blue-Howells, \& Seldin-Sommer, 2009; Goldberg et al., 1968).

This article reports the findings from a small, qualitative study conducted in Aotearoa New Zealand which explored: a) the perceptions of key stakeholders about this kind of social work integration; and $b$ ) the experiences gained by integrated $\mathrm{PHCP}$ social workers regarding their contributions towards the PHC vision. A contemporary view of the potential for the social work profession within PHCPs is offered and understanding about this model within an Aotearoa New Zealand context is broadened. The study was briefly reported in Döbl, Huggard and Beddoe (2015). This article explores in greater detail the themes arising from the analysis of the qualitative data.

\section{Method}

A qualitative approach was selected for the study as this strategy enables researchers to increase their understanding about a field where little is known about the lived experience of those participating in a specific human activity. Qualitative research uses "words as data" (Braun \& Clarke, 2013, p. 4), and enables the researcher to generate rich data for analysis and give voice to the participants, and was appropriate for this small exploratory study. Further, this approach provided an opportunity for participants within the field to share their expert knowledge, ideas and experiences (Morse \& Richards, 2007). The methodology chosen was qualitative description which "is the method of choice when straight 
descriptions of phenomena are desired" (Sandelowski, 2000, p. 339). This strategy provided a way to not only gain first insight into the topic but also to stay close to the data. Qualitative description is appropriate when professionals' views with a particular topic are sought because such study "presents the facts from exactly the informant's points of view" and recognises the participants' knowledge and practice experiences (Neergaard, Olesen, Andersen, \& Sondergaard, 2009, p. 4).

\section{Participants and sampling}

Three participant groups were interviewed: social workers, other PHC professionals and key informants. The decision to focus on three key groups enabled not only exploration of the topic in more breadth and depth but also seemed crucial given that PHC provides a host setting for the social work profession (Beddoe, 2017) and thus its presence is dependent on working relationships with other practitioners from other professions.

Various sampling strategies secured the recruitment of overall 18 participants nationwide. First, social workers who were members of the Aotearoa New Zealand Association of Social Workers (ANZASW) received an invitation by email to participate in the study. This group involved nine qualified social workers who had worked in a PHCP.

The second group, professionals other than social workers in PHC were accessed via professional networks using a snowball technique. This PHC professionals group included two qualified general practitioners (GPs) and one registered nurse who had worked with, or had a special interest in working with, a social worker in a PHCP. The third group consisted of six key informants who had a good understanding of PHC, social work, or both. These key informants had management or decisionmaking level positions within their employment or professional association/ college. Given the small scale of PHCP social work, no further details are provided in order to ensure the anonymity of participants.

\section{Ethics approval}

The study was conducted for the fulfilment of a Master of Health Sciences degree. Ethics approval for this qualitative study was obtained from The University of Auckland Human Participants Ethics Committee. In addition, professional bodies and other relevant organisations granted approval following their own internal ethics review of the research proposal.

\section{Data collection and analysis}

The semi-structured interviews took place in 2012, four face-to-face and 14 by telephone depending on the preference and location of the participants. The interview length varied between 40 to 105 minutes. The findings of the literature review provided the basis for the interview questions which covered four topic themes: having an understanding of PHC and models of integrated care; reasons and attractions for social workers to work in PHCPs; scope of this integrated social work practice; and the achievements of, and challenges faced by, social workers positioned in PHCPs. All participants consented to having their interviews audiotaped which were then transcribed verbatim and loaded into the NVivo 10 software programme (QSR International, 2012). All participants could select a pseudonym of their choice for reporting the data.

The data analysis used a general inductive approach (Thomas, 2006). After reading the transcripts several times, text segments were coded, combined, and aggregated further into themes according to similarity (Creswell, 2002; Thomas, 2006). This process allowed conveying the major idea of each theme. A health professional working independently of the researcher reviewed codes and themes. There was a high level of agreement. 


\section{Findings}

Three key themes, "Social Work Factors", "Organisational Factors" and "Wider Factors", as well as 10 sub-themes were developed from analysis of the interview data. Participants' quotes in the text illustrate the findings.

\section{Social work professional factors}

The first key theme focuses on the social work profession itself. These professional factors are apposite to the PHC vision, influenced by, but also impacting on, the other two key themes.

\section{Role clarification by the social work profession}

Participants across all three groups identified a fundamental need to clearly articulate the aims and skills of the social work profession when working in a PHCP. Social workers must be able to clearly communicate their specific role within their organisational context to all stakeholders. The participating social workers accepted responsibility for addressing this key challenge long-term. They used different, successful strategies such as presentations to their team members and wider community. This finding was reinforced by this key informant:

I think the most important thing and I think it's probably the thing that social workers do least well is articulate ... what social work is and does. That makes it different from nursing, from general practice,... and all of those other counselling, psychology type services... it becomes critically important that a social worker can articulate what the profession does in a professional service. (Lucy, ANZASW)

\section{Social work perspectives and knowledge}

The social workers' perspectives and theoretical knowledge reflected both the international and national definitions of social work (ANZASW, 2013; IFSW, 2014). Participants identified "social justice" and "equity" as key principles for their practice. All social work participants placed a strong notion of seeing people holistically within their context, emphasising that the term holistic referred to all aspects of health including people's lived environments and the interconnectedness of these aspects. Hence, they incorporated holistic models such as Te Whare Tapa Whai (Durie, 1998) and Fonofale ${ }^{\mathrm{ii}}$ (Pulotu-Endermann, 2001) into their practice. Andrea, a social worker in a general practice, further explained:

... you can actually work with anybody in the family if working with the husband will help the wife's health. Working with the children-working with the Mum will help the children's health. It's all interconnected so you can really just get in there and work as part of the medical team but in the community.

Another crucial social work aspect identified was that of supporting people's self-determination and working with the "pace" of a person. Social workers used systematic strategies such as ensuring proper consent and focusing on the concerns of the referred person (and not only following referrers' requests). In addition, the social workers had extensive and practical knowledge about health information, clients and families, their own PHCP as well as services and their processes in the health, government, social and community sectors.

\section{Social work phases}

The social work participants worked methodically towards achieving set goals by following commonly applied social work phases. These phases were referral, preparation, building rapport, assessment, setting goals and establishing a joint plan with clients (and their families) followed by tailored interventions which were continuously monitored and reviewed, closure. 
How important an assessment is was emphasised by Lucy, ANZASW key informant:

That's fundamental to a social work intervention, is doing a good assessment and being guided by the person they're working with because they are the experts in what's going on for them and it's the social work task to do that assessment in the context of the whole person's life. Not just here's a person in front of me with an alcohol problem, it's what's happening in their families, in their immediate environment, their community, their employment.

Consistently through these phases, the social work participants showed on-going flexibility (e.g., ways of initiating and keeping contact, location of appointments, involvement of supportive and critical other people, adjusting to new situations). Interventions included advocacy, case management, liaison, referrals, information provision, practical and emotional support, counselling, health education, skill building and group work among others. Regular follow-ups with clients and other stakeholders as well as ensuring successful referrals to other (long-term social work) services when required were of particular significance to the social workers. All participant groups identified further potential for the social work profession within PHCPs. Possible areas of future activity included "advanced care planning"; "violence intervention programs"; "community development"; and assessing an organisation's "health literacy."

\section{Relationship building by social workers}

The social workers emphasised the importance of relationships for their work with people, perceiving it as fundamental for best social work practice. Building rapport and empowering relationships were thereby significant aspects, especially for working successfully with clients and their families as well as facilitating team work within the PHCP.

Another objective was to work with clients and others to ensure appropriate, timely access and smooth pathways to services. Relationships within the wider health and social service networks were needed to facilitate collaboration and ensure wellcoordinated health care. Therefore, the social workers developed extensive relationships with external stakeholders across a range of sectors, including: health and disability, government, community, housing, education, and justice/legal. Further connections were maintained with cultural and spiritually based organisations. The impact of this approach is explained by Lisa, a PHC nurse in a busy urban practice:

I saw the social worker I was working with develop really strong relationships within ... and outside the service and as a nurse that also enabled me to then develop such relationships ... which was essential in addressing the needs of a complex population.

\section{Social workers ensuring the flow of effective and clear communication}

The social work participants highlighted their important role of being a central link that ensured continuous communication between clients and their families, health professionals and external agencies. Special significance was given to this aspect when dealing with (potential) safety issues such as child abuse and neglect, domestic violence or serious mental health concerns. As highlighted by Tiaki, social worker, Whanau Ora ${ }^{\text {iii }}$ (The Tangata Whenua, Community \& Voluntary Sector Research Centre, 2016): "I think the important thing working in primary care is that you have some ultimate, critical communications going on within your team, from doctors right across the board to community health workers, administrators." 
The social workers shared regularly information, including feedback to the referrer about details of their social work involvement. In order to enhance a timely exchange, social workers used various communication strategies such as computer case notes, ad hoc consultations and formal team meetings. Participants from all three groups thought that information sharing would be eased by being located as a team within the same PHCP.

\section{Being a safe social work practitioner}

Being a safe practitioner was of huge importance to all social work participants. They felt even more obligated about this aspect as they were usually the sole social worker within their PHCP. The social workers differentiated between professional and personal safety. The first aspect was linked to accountability, representing a mechanism to ensure best social work practice. They felt accountable towards all stakeholders, especially clients and their families, and used diverse strategies. Examples included professional reliability, continuous evaluation of their social work practice as well as professional membership and registration. The social work participants highlighted the crucial access to, and the role of, supervision. The aspect of personal safety referred to the issue of potential threats to their own health, especially when working outside the PHC practice. The social workers identified the importance of carefully planned home visits in order to ensure that the specific home was safe to enter (e.g., dogs at the property are restrained if necessary). The participants used various strategies to ensure their personal safety: informing colleagues about their whereabouts and working together with other professionals (such as the women's refuge). Lara, social worker in a PHCP, summarised what other social workers also emphasised:

I guess the big thing is to have very good systems around you. You've got to be well supervised, you've got to have a clear vision of what your role is and what its limitations are and a very strong safety net in place around practice standards and accountability.

\section{Organisational factors}

Organisational factors comprise the second key theme and reveal more about the environments in which social workers operated. The two identified sub-themes focused on community needs and providing a supportive work environment.

\section{Focusing on needs}

Participants from all three groups had a strong desire to purposefully place social workers within PHCPs. Most felt that establishing such positions was long overdue. The rationale was manifold. Participants argued that PHC practices are contracted to deliver first contact and close to home health care. Such care is provided to all people over their life course, without referrals and independently of people's health concerns and status. Hence, PHCPs are confronted by an array of issues experienced by the accessing population on a daily basis. Given the nature and the complexity of these health issues, participants wished to offer more holistic health care to their practice population and identified the need for an additional skilled profession such as social work to offer such service. The participants also desired a seamless, preventive and early intervening PHC provision built on trust and close relationships. Many of these professionals had experienced fragmented, delayed and uncoordinated care, resulting in adverse health outcomes for especially vulnerable populations. Jason, GP, offered this view:

The more comprehensive the team is in primary care, the more problems they can deal with themselves without needing to refer anywhere else and the more effective they are because the more you fragment care, the less efficient it is.

Participants preferred the integration of social work roles within PHCPs compared to other options such as collaboration via referrals to community social work services, within and beyond the health sector. 
However, they identified barriers to this inclusion, especially in smaller PHCPs where funding and space were concerns.

All participant groups agreed that the focus needed to be on populations who were most affected by health inequalities (such as Mãori people, Pasifika peoples, people living with high deprivation) or who were vulnerable due to their age (e.g., children), had high health needs (e.g., people with a mental health diagnosis) or were new to the country (migrants and refugees).

\section{A supportive work environment}

Overall, social work participants felt strongly supported by their PHC practices which included cultural support. The social workers also appreciated the good employment conditions offered within their various organisations. The access to professional resources, including peer and external supervision, professional development, and payment of professional membership fees was especially valued.

Despite these positive experiences, participants identified two key challenges. The first challenge was one of professional isolation which originated from the fact that social work roles within PHCPs are usually sole positions. Therefore, additional skills such as the ability to establish clear role boundaries as well as having a strong professional identity and social work community links are required. This challenge was pro-actively managed by the social workers and was also minimised due to the commitment of their PHCPs. Jackie, GP at an urban practice, confirmed the need for this support:

... if you were employing them as a practice you would need to provide them with what they need, some paid supervision, paid mentoring and the respect for listening to their feedback ... they'd need to be ... supported within the team. Because being one of one modality in a team I think is really hard.
Some social workers and the nurse participant observed a second challenge, namely issues of equality and power. They observed these issues on various levels: between clients and health professionals, between professions, and within the health care system. Comments mainly referred to a "dominant Western health care model" which reinforces power imbalances. Further, the social workers felt responsible to advocate for their clients, not only outside but also within, their employing practice, which proved difficult at times.

\section{Wider factors}

The final key theme provides the context for integrating social workers within PHCPs as part of the broader health care system in Aotearoa New Zealand. Two environmental aspects were identified in the data analysis within this theme: challenges related to funding concerns and communities' health experiences.

\section{The funding challenge}

All research participants identified funding as a major, constant challenge regarding the integration of the social work profession within PHC practices. There was general consensus that the government as the funding authority needed to allocate money for initiating and sustaining this integrative PHC model. However, the participants experienced problems with funding formulas and funding "dried up" on a regular basis. Given that sustainable change and outcomes related to health inequalities often take time, most participants questioned whether any government would commit sufficient resources long term to such an innovative approach, especially in times of fiscal restraints. Overall, it was indicated that the social work profession had to provide evidence of its usefulness with respect to financial gains rather than to improved health care provision. Participants cautioned that this was a complex task. One participant shared her observation: 
...this person who I've been working with in the past few weeks who I've not been able to have social work support with, has presented three to four times, each time seeing a different GP probably for more than half an hour, so that's two and a half hours of GP time, nothing has actually been addressed about the things she's coming in with so in terms of time and money I'm sure that it would definitely be cost efficient to have more social workers. (Lisa, PHC nurse in a busy urban practice)

\section{Health and social issues experienced by communities}

All participants identified an array of issues experienced by communities which covered all aspects of their health (physical, mental, emotional, cultural, spiritual, and family) and reflected the social determinants of health. Examples included but were not limited to: transport, food insecurity, conflict at work, unemployment, obesity, terminal illness, disability, depression, grief and loss, anger, adaption to chronic conditions, immigration problems, family conflicts, parenting problems, domestic violence, and child abuse. Other issues observed were difficulties of access to, and engagement with, organisations (e.g., non-attendance of appointments). Anna, Royal New Zealand College of General Practitioners (RNZCGP) key informant, explained:

That's their whole background. Definitely money, housing, lack of support, lonely, don't know where to turn to, stressed to the max and it's just entirely their living and they're presenting with physical symptoms that we can't treat until we sort out their home environment.

Further, participants reported about challenges experienced commonly by certain populations due to their age or life transitions. For example, elderly clients faced issues around independent living, caregiver concerns, isolation, and dementia. Poverty was of particular concern to participants due to its extent in Aotearoa New

Zealand and its health impacts on whole communities. The social workers reported that clients frequently experienced multiple, interconnected health concerns, either for themselves, within their families or both.

The consensus among all three participant groups was that social workers were the right profession to support communities in addressing these wider health challenges in the particular host setting of a PHCP; because communities presented in their own ways to their health care providers.

\section{Discussion}

Participants from all three groups demonstrated consensus regarding these themes despite their diverse backgrounds. A few, minor, differences were observed.

The social work factors embody the aspects crucial to the social work profession in general and particularly when working in a PHC practice. Overall, the findings reflected international and national professional concerns drawn from the wider health social work literature. For example, participants emphasised the importance of all stakeholders having a clear understanding about social work, both social work practice and its context-specific roles, as these positions can and do often vary. Such clarity is important considering that health care systems and its professions are in a constant state of flux (Weld, 2010).

Participants reported further factors which illustrate what makes social work unique, setting it apart from any other profession in the PHC team. As outlined, social work brings together a particular combination of values, knowledge, approaches and skills. Examples include the profession's theoretical foundations (Keefe et al., 2009), processes (Ní Raghallaigh, Allen, Cunniffe, \& Quin, 2013), relationship and coordination skills (which enhance the horizontal and vertical integration of care increasingly demanded within health care systems), communication 
skills (Foster \& Beddoe, 2012) and professional responsibility to access appropriate supervision in order to practise ethical social work (ANZASW, 2013). Social work offers thus a distinctive benefit to an integrated PHC team because of their access to, and their engagement with, communities who are most affected by health inequalities, who experience high health needs, or both. This study also shows that social workers can be vital to a PHCP due to enhancing quality and coordination of care, increasing safety, strengthening the workforce as well as extending the knowledge of their own profession and key stakeholders.

Encouragingly, all social work participants emphasised their overall positive experience in working in PHC practices despite various challenges and recommended this field to other social workers.

The organisational and wider factors provided the context in which integrated PHCP social workers operated in. These environments determined whether best social work practice can be delivered. The organisational factors referred to the focus on community needs and providing a supportive work environment for social workers. A strong support for purposefully positioning social workers in PHCPs was reported. All participants identified the social work profession as an asset to PHC teams and in particular when the accessing communities faced significant health and social inequalities. Such a fit is reiterated in international health literature (Bikson et al., 2009; Bywaters \& Napier, 2009; Dongray, 1958; Döbl et al., 2015). Having a supportive, responsive and secure base within the PHCP is one crucial requirement to make social work integration successful, especially if employing only one social worker. Evidence regarding challenges commonly experienced by social workers in health care organisations and the importance of supportive work environments can be widely found (Beddoe, 2013; IFSW, 2012; Kharicha, Iliffe, Levin, Davey, \& Fleming, 2005; Lymbery, 2006; Ní Raghallaigh et al., 2013).
Funding concerns and the diverse health challenges experienced by communities were of greatest significance. National evidence points to the particular barrier regarding the current PHC funding system (Pullon, 2007). Getting the system right is critical in order to reflect and facilitate that integrated PHC is delivered by a team of diverse health professionals (Workforce Taskforce, 2008). The identified health issues which communities experienced and presented to PHCPs reflect the international evidence within health social work (Bikson et al., 2009; Coren, Iredale, Rutter, \& Bywaters, 2011; Craig et al., 2016; Gross, Gross, \& EisensteinNaveh, 1983). Special mention is warranted for the potential for integrated social workers to address psychosocial issues in the event of terrorism or natural disasters (Gross et al., 1983). In Aotearoa New Zealand, PHC practices played a crucial role in supporting survivors of the Christchurch earthquakes; this support continues today. Overall, the research study highlights that appropriate funding has to be located which requires explicit understanding about the PHC vision and a long-term commitment to achieve this vision by financial decision-makers on all levels.

\section{Conclusion}

Overall, this study strengthens our understanding of the potential for comprehensive, integrated PHC service delivery incorporating a social work contribution. Some limitations need to be considered. Being a small, exploratory, qualitative study, generalisations are restricted regarding other integrated PHCP social work positions in Aotearoa New Zealand. The focus on a limited number of PHC professions with specific selection criteria does not reflect the professional diversity within the sector and limits alternative views about this PHC model. The study also excluded other major stakeholders such as families and communities.

This research demonstrates that the positioning of social work professionals 
within PHCPs is a viable and successfully implemented model in Aotearoa New Zealand, although these are limited in numbers at present. Participants described the benefits of such social work integration and its future potential, thus suggesting the need for greater engagement between the PHC sector and the social work profession. This model should be considered by key stakeholders when developing comprehensive, integrated PHC services with their local communities, especially when serving populations most affected by health and social inequalities.

\section{References}

Aotearoa New Zealand Association of Social Workers. (2013). Code of ethics (3rd Rev. ed.). Christchurch, New Zealand: Author.

Backett, E. M., Maybin, R. P., \& Dudgeon, Y. (1957). Medicosocial work in a general practice. The Lancet, 269, 37-41. doi.org/10.1016/s0140-6736(57)92454-6

Beddoe, L. (2013). Health social work: Professional identity and knowledge. Qualitative Social Work, 12, 24-40. doi.org/10.1177/1473325011415455

Beddoe, L. (2017). Field, capital and professional identity: Social work in health care. In S. Webb (Ed.), Professional identity in social work (pp. 122-135). Oxon, UK: Routledge.

Beddoe, L., \& Deeney, C. (2012). Discovering health social work in New Zealand in its published work: Implications for the profession. Aotearoa New Zealand Social Work, 24(1), 41-55.

Bikson, K., McGuire, J., Blue-Howells, J., \& Seldin-Sommer, L. (2009). Psychosocial problems in primary care: Patient and provider perceptions. Social Work in Health Care, 48, 736-749. doi.org/10.1080/00981380902929057

Braun, V., \& Clarke, V. (2013). Successful qualitative research: A practical guide for beginners. London, UK: Sage.

Brochstein, J. R., Adams, G. L., Tristan, M. P., \& Cheney, C. C. (1979). Social work and primary health care: An integrative approach. Social Work in Health Care, 5, 71-81. doi.org/10.1300/J010v05n01_08

Bywaters, P., \& Napier, L. (2008). Health. Retrieved from http://ifsw.org/policies/health/Bywaters, P., \& Napier, L. (2009). Revising social work's international policy statement on health: Process, outcomes and implications. International Social Work, 52, 447-457. doi.org/10.1177/0020872809104249

Coren, E., Iredale, W., Rutter, D., \& Bywaters, P. (2011). The contribution of social work and social interventions across the life course to the education of health inequalities: A new agenda for social work education? Social Work Education: The International Journal, 30, 594-609. doi.org/10.1080/02615479.2011.586556

Craig, S., Frankford, R., Allan, K., Williams, C., Schwartz, C., Yaworski, A., . . Malek-Saniee, S. (2016). Self-reported patient psychosocial needs in integrated primary health care: A role for social work in interdisciplinary teams. Social Work in Health Care, 1-20. doi:10.1080/0098138 9.2015.1085483
Craig, S. L., \& Muskat, B. (2013). Bouncers, brokers, and glue: The self-described roles of social workers in urban hospitals. Health \& Social Work, 38, 7-16. doi.org/10.1093/hsw/hls064

Creswell, J. W. (2002). Educational research: Planning, conducting and evaluating quantitative and qualitative research. Upper Saddle River, NJ: Pearson Education.

Curry, N., \& Ham, C. (2010). Clinical and service integration. The route to improved outcomes. Retrieved from https://www.kingsfund.org.uk/sites/files/kf/Clinicaland-service-integration-Natasha-Curry-Chris-Ham-22November-2010.pdf

Döbl, S., Huggard, P., \& Beddoe, L. (2015). A hidden jewel: Social work in primary health care practice in Aotearoa New Zealand. Journal of Primary Health Care, 7(4), 333-338.

Dongray, M. (1958). Social work in general practice. The British Medical Journal, 2, 1220-1223. doi.org/10.1136/bmj.2.5106.1220

Durie, M. (1998). Whaiora: Maōri health development. Auckland, New Zealand: Oxford University Press.

Foster, S., \& Beddoe, L. (2012). Social work with older adults in primary health-Is it time to move our focus? Aotearoa New Zealand Social Work Review, 24(2), 37-48.

Goldberg, E. M., Neill, J., Speak, B. M., \& Faulkner, H. C. (1968). Social work in general practice. The Lancet, 292, 552-555. doi.org/10.1016/s0140-6736(68)92421-5

Gross, A. M., Gross, J., \& Eisenstein-Naveh, A. R. (1983). Defining the role of the social worker in primary health care. Health \& Social Work, 8, 174-181. dx.doi. org/10.1093/hsw/8.3.174

Herod, J., \& Lymbery, M. (2002). The social work role in multi-disciplinary teams. Practice, 14(4), 17-27. doi.org/10.1080/09503150208411539

International Federation of Social Workers. (2012). Effective and ethical working environments for social work: The responsibilities of employers of social workers. Retrieved from http://ifsw.org/policies/effective-and-ethical-workingenvironments-for-social-work-the-responsibilities-ofemployers-of-social-workers-3/

International Federation of Social Workers. (2014). Definition of social work. Retrieved from http://ifsw.org/policies/ definition-of-social-work/

Keefe, B., Geron, S., \& Enguidanos, S. (2009). Integrating social workers into primary care: physician and nurse perceptions of roles, benefits, and challenges. Social Work in Health Care, 48, 579-596. doi.org/10.1080/00981380902765592

Kharicha, K., Iliffe, S., Levin, E., Davey, B., \& Fleming, C. (2005). Tearing down the Berlin wall: Social workers' perspectives on joint working with general practice. Family Practice, 22, 399-405. doi.org/10.1093/fampra/cmi010

King, A. (2001). The primary health care strategy. Retrieved from http://www.health.govt.nz/publication/primaryhealth-care-strategy

Laden, S., Oehlers, M. J., Waddell, A. J., \& Miller, N. B. (1983). Social work and general practice in Western Australia. Australian Social Work, 36(1), 37-38. doi.org/10.1080/03124078308549747

Lesser, J. (2000). Clinical social work and family medicine: A partnership in community service. Health \& Social Work, 25, 119-126. doi.org/10.1093/hsw/25.2.119 
Lowe, J. L., \& Rainey, H. B. (1974). Social work in a New Zealand group medical practice. New Zealand Medical Journal, 79, 739-742.

Lymbery, M. (2006). United we stand? Partnership working in health and social care and the role of social work in services for older people. British Journal of Social Work 36, 1119-1134. doi.org/10.1093/bjsw/bch348

Lymbery, M., \& Millward, A. (2002). Community care in practice: Social work in primary health care. Social Work in Health Care, 34, 241-259. doi.org/10.1300/ J010v34n03_01

Minister of Health. (2016). New Zealand Health Strategy: Future direction. Wellington, NZ: Author.

Morse, J. M., \& Richards, L. (2007). Readme first for a user's guide to qualitative methods (2nd ed.). Thousand Oaks, CA: Sage Publications.

Neergaard, M., Olesen, F., Andersen, R., \& Sondergaard, J. (2009). Qualitative description-The poor cousin of health research? BMC Medical Research Methodology, 9(1), 52. doi.org/10.1186/1471-2288-9-52

Netting, F. E., \& Williams, F. G. (1996). Case managerphysician collaboration: Implications for professiona identity, roles, and relationships. Health Social Work, 21 216-224. doi.org/10.1093/hsw/21.3.216

Ní Raghallaigh, M., Allen, M., Cunniffe, R., \& Quin, S. (2013) Experiences of social workers in primary care in Ireland. Social Work in Health Care, 52(10), 930-946. doi.org/10. 1080/00981389.2013.834030

Nuthall, J. J., \& Craig, T. (1980). Social work and patient care in a medical centre. The New Zealand Medical Journal, 92(674), 471-474.

Pullon, S. (2007). Teamwork: A fundamental principle of primary health care and an essential prerequisite for effective management of chronic conditions. New Zealand Family Physician, 34, 318-321.

Pulotu-Endermann, F. K. (2001). Fonofale. Model of health. Presentation at the workshop of Massey University, Wellington, NZ. Retrieved from http://www.hauora. co.nz/resources/Fonofalemodelexplanation.pdfQSR International. (2012). NVIVO 10. [Computer software]. Retrieved from http://www.qsin ternational.com/ products_nvivo_pricing.aspx

Rizzo, V., \& Mizrahi, T. (2008). Perceptions on the roles and value of social work practice in neighbourhood health centers and implications for the reimbursement of services. Social Work in Public Health, 23(6), 99-125. doi.org/10.1080/19371910802059668

Rock, B. D., \& Cooper, M. (2000). Social work in primary care: A demonstration student unit utilizing practice research. Social Work in Health Care, 31(1), 1-17. doi. org/10.1300/J010v31n01_01

Sandelowski, M. (2000). Whatever happened to qualitative description? Research in Nursing \& Health, 23, 334-340. doi.org/10.1002/1098-240X(200008)23:4<334::AIDNUR9>3.0.CO;2-G

Shaw, S., Rosen, R., \& Rumbold, B. (2011). What is integrated care? Retrieved from http://www.nuffieldtrust. org.uk/sites/files/nuffield/publication/what_is_integrated_ care_research_report_june11_0.pdf

The Tangata Whenua, Community \& Voluntary Sector Research Centre. (2016). About Whánau Ora. Retrieved from http://whanauoraresearch.co.nz/about-whanau-ora/
Thomas, D. R. (2006). A general inductive approach for analyzing qualitative evaluation data. American Journal of Evaluation, 27(2), 237-246. doi. org/10.1177/1098214005283748

Weld, N. (2010). Resuscitating health social work. Aotearoa New Zealand Social Work Review, 21/22(4/1), 25-33.

Wilson, J., \& Setturlund, D. (1987). Towards holistic social work practice in general medical settings. Social Work in Health Care, 12(2), 1-13. doi.org/10.1300/ J010v12n02_01

Workforce Taskforce. (2008). Working together for better primary health care: Overcoming barriers to workforce change and innovation. Retrieved from http://www. health.govt.nz/publication/working-together-betterprimary-health-care

World Health Organization (WHO). (1978). Alma Ata Declaration. Retrieved from http://www.who.int/ publications/almaata_declaration_en.pdf?ua=1

World Health Organization (WHO). (1986). The Ottawa Charter for Health Promotion. Retrieved from http://www. who.int/healthpromotion/conferences/previous/ottawa/ en/

World Health Organization. (2008). The World Health Report. Primary health care-Now more than ever. Retrieved from http://www.who.int/whr/2008/en/

\section{End Notes}

Māori Model of Health.

Pacific Island Model of Health.

iii Māori approach of providing holistic support services to the family as a whole. 